\title{
Progressive Steps of Polymorphic Transformation of Gabapentin Polymorphs Studied by Hot-stage FTIR Microspectroscopy
}

\author{
Cheng-Hung $\mathrm{Hsu}^{1}$, Wen-Ting $\mathrm{Ke}^{1}$ and Shan-Yang $\mathrm{Lin}^{2} *$ \\ 1. Depart. Res. and Develop., Orient Pharma Co., Ltd., Taoyuan, Taiwan \\ 2. Lab. Pharm. Biopharm., Department of Biotechnology, Yuanpei University, Hsin Chu, Taiwan Republic of China
}

Received, August 19, 2009; Revised, October 13, 2010; Accepted, March 29, 2010; Published, March 31, 2010.

\begin{abstract}
Purpose. The aim of this study was to determine the progressive processes of polymorphic transformation of different gabapentin (GBP) polymorphs by using hot-stage Fourier transform infrared (FTIR) microspectroscopy. Methods. Four polymorphs of GBP were previously prepared and then identified by differential scanning calorimetry (DSC), thermogravimetric (TG) analysis, FTIR microspectroscopy and X-ray powder diffractometry. A novel hot-stage FTIR microspectroscopic technique was used to investigate the progressive steps of polymorphic transformation of each GBP polymorph sealed within two pieces of KBr plates. Results. Four polymorphs (Forms I, II, III and IV) of GBP were well characterized. The GBP form I was proven to be a monohydrate, but other GBP forms II-IV were anhydrous. Different thermal-induced progressive processes and steps of polymorphic interconversion of GBP polymorphs were clearly found from the changes in the three-dimensional IR spectral contour and peak intensity by using hot-stage FTIR microspectroscopy. The results also indicate that GBP form I was dehydrated and transformed to form III, and then converted to form IV; whereas GBP forms II and III directly transformed to form IV during heating. The GBP form IV was the last polymorph before the intramolecular lactamization of GBP. Conclusion. A one-step novel hot-stage FTIR microspectroscopy was successfully applied to simultaneously and continuously investigate the progressive processes and steps of thermal-induced polymorphic interconversion of GBP polymorph in the solid state.
\end{abstract}

\section{INTRODUCTION}

Gabapentin (GBP) has been widely used as an anticonvulsant for the treatment of epilepsy (1). New indications of GBP have been recently recommended for treating posttherpetic neuralgia, other painful neuropathies and nerve related pains (2-3). Moreover, GBP as a possible treatment of neurodegenerative diseases like Alzheimer's is also demonstrated (4). Although the detailed mechanism of action of GBP is still unknown, it has been proposed that GBP consisted of a 1, 1-disubstituted cyclohexane ring and could form two interconvertible chair forms for possible interaction at a potential receptor site (5-6). In addition, GBP has been designed as a $\gamma$-aminobutyric acid (GABA)-mimetic agent to freely cross the blood-brain barrier, resulting in higher level of GBP in the brain for treatment of partial seizures (7-8).

The solid-state characteristics of a drug substance are well known to significantly affect its physicochemical properties, such as melting point, optical and mechanical properties, density, chemical reactivity, apparent solubility and intrinsic dissolution rate (9-10). Different physicochemical characterizations of a drug substance not only can directly influence the manufacturing process of drug itself and drug product, but also can cause the stability and dissolution of drug product, leading to changes in bioavailability. The most important issue for solid-state chemistry of drugs is polymorphism and/or crystal forms (11). In a drug substance exhibiting polymorphism, the polymorphs may exhibit different physicochemical properties resulting in the alteration in quality, safety, and efficacy of the drug product.

GBP has been reported to exist in the zwitterion form in the solid state or easily form a GBP-lactam via intramolecular cyclization (12-13). Until now, four GBP polymorphs have been reported in many patent applications and issued patents (14-16).

\footnotetext{
Corresponding Author: Prof. Shan-Yang Lin, Ph.D. Lab. Pharm. Biopharm., Department of Biotechnology, Yuanpei University, Hsin Chu, Taiwan, ROC

E-mail: sylin@mail.ypu.edu.tw
} 
Although different nomenclatures in patents and literatures had been used, two recent studies have unified these (17-18). The crystal structure of each GBP polymorph exhibit different hydrogen bonding strengths between $\mathrm{NH}_{3}{ }^{+}$and $\mathrm{COO}^{-}$groups of neighboring molecules (19). The active pharmaceutical ingredient (API) of marketed GBP is anhydrous form II, whereas the GBP form I is a monohydrate (17, 20-21). More recently, GBP monohydrate has also been proven to have two polymorphic forms (22). However, there is scant report describing the thermal-induced polymorphic interconversion of such GBP polymorphs in the solid state although an alternate crystal form (cocrystal) of GBP with oxalic acid had been reported $(17,23)$. Therefore, the purpose of this study was first to prepare these four GBP polymorphs and then to identify these polymorphs by using differential scanning calorimetry (DSC), thermogravimetric (TG) analysis, Fourier transform infrared (FTIR) microspectroscopy and X-ray powder diffractometry. Furthermore, the thermal-induced progressive processes and steps in polymorphic interconversion of each GBP polymorph in the solid state were studied by a novel hot-stage FTIR microspectroscopy.

\section{MATERIALS AND METHODS}

\section{Materials}

A pharmaceutical grade of gabapentin (GBP, Lot No. PN63415, Sun Pharma. Ind. Ltd., Gujarat, India) was used without further purification. The commercial API of GBP used in this study was proven to be form II $(2,13,15)$. An analytical reagent grade of $\mathrm{KBr}$ cubic crystal $(5 \mathrm{~mm} \times 5 \mathrm{~mm}$ x $5 \mathrm{~mm}$, Jasco Co., Tokyo, Japan) was cut into thin plate-like pieces for use.

\section{Preparation of different GBP polymorphs}

\section{Form I}

A saturated solution of GBP dissolved in double distilled water at $40^{\circ} \mathrm{C}$ was stored in a refrigerator at $4^{\circ} \mathrm{C}$ for one day. The precipitated crystals were isolated by filtration.

\section{Form II}

The commercial API of GBP used without further purification was characterized to be form II $(2,13$, $15)$.

\section{Form III}

The GBP form III was prepared by rapidly heating the GBP form I to $85^{\circ} \mathrm{C}$ in a DSC system (DSC-910, TA Instruments Inc., New Castle, DE, USA) and isothermally maintained at $85^{\circ} \mathrm{C}$ for $3 \mathrm{hrs}$, and then cooled to $25^{\circ} \mathrm{C}$.

\section{Form IV}

The GBP form IV was prepared by rapidly heating the GBP form III to $120^{\circ} \mathrm{C}$ in a DSC system and isothermally maintained at this temperature for 90 min, and then cooled to $25^{\circ} \mathrm{C}$.

\section{Identification of each GBP polymorph}

Each GBP polymorph was identified using FTIR microspectroscopy (Micro FTIR 200, Jasco Co., Tokyo, Japan; transmission mode) by sealing the sample between two pieces of $\mathrm{KBr}$ plates (13, 24-25), and also by differential scanning calorimetry (DSC, TA Instruments Inc., New Castle, DE, USA) at a heating rate of $3^{\circ} \mathrm{C} / \mathrm{min}$ with an open pan system in a stream of $\mathrm{N}_{2}$ gas from 30 to $260^{\circ} \mathrm{C}$. FTIR spectra were generated by co-addition of 256 interferograms collected at 4 $\mathrm{cm}^{-1}$ resolution. Temperature and heat flow of DSC system were calibrated by standard indium sample. Thermogravimetric (TG) analysis (TGA-951, TA Instruments Inc., New Castle, DE, USA) was carried out using the heating rate of $3^{\circ} \mathrm{C} / \mathrm{min}$ to measure the weight loss of each GBP polymorph. The X-ray diffraction pattern of each polymorph was also recorded using a powder X-ray diffractometer (Miniflex, Rigaku, Japan) under the following conditions: $\mathrm{CuK} \alpha$ radiation; current, 30 $\mathrm{mA}$; voltage, $50 \mathrm{kV}$; scanning rate, $2^{\circ} / \mathrm{min}$; scanning angle, $2 \theta$; scanning range, $5-60^{\circ}$.

\section{Hot-stage FTIR microspectroscopic study}

A trace amount of each GBP polymorph was sealed between two $\mathrm{KBr}$ plates by a hydraulic press under $200 \mathrm{~kg} / \mathrm{cm}^{2}$ for 15 seconds to form a disc (13, 24-25). Each sample disc was then placed onto a hot-stage (DSC microscopy assembly, FP 84, Mettler, Greifensee, Switzerland). This DSC microscopy assembly was then directly set on the stage of a FTIR microscopic spectrometer with a mercury cadmium telluride (MCT) detector by determining with a transmission method. The temperature of the DSC microscopy assembly was monitored with a central processor (FP 80HT, Mettler, Greifensee, Switzerland). Each sample disc was previously equilibrated to the starting temperature $\left(30^{\circ} \mathrm{C}\right)$ and then heated to $200^{\circ} \mathrm{C}$ at a heating rate of $3^{\circ} \mathrm{C} / \mathrm{min}$. The thermal-responsive IR 
spectra were simultaneously recorded in the course of heating process.

\section{RESULTS AND DISCUSSION}

\section{Identification of different GBP polymorphs}

The DSC and TG curves of four GBP polymorphs are shown in Fig. 1. The predominant endothermic peaks were observed at $169-171^{\circ} \mathrm{C}$ for these four BGP polymorphs, attributed to the melting of GBP $(12-13,26)$. Another small endothermic peak at $68^{\circ} \mathrm{C}$ was only observed in the DSC curve of GBP form I. This endothermic peak correlated to the weight loss in the TG curve. The weight loss near $55-75^{\circ} \mathrm{C}$ in TG curve was about $9.35 \%$, equal to one mole of water lost from GBP form I, indicating that GBP form I was a monohydrate. Since all DSC and TG curves exhibited similar patterns for these four GBP polymorphs except for the initial dehydration process of GBP form I, it indicates that there was no significant difference among these curves. The complete weight loss for each GBP polymorph was also found in TG curves after $140-150^{\circ} \mathrm{C}$. This might be due to the combined processes of intramolecular lactamization of GBP and evaporation of GBP-Lactam (13).

Fig. 1

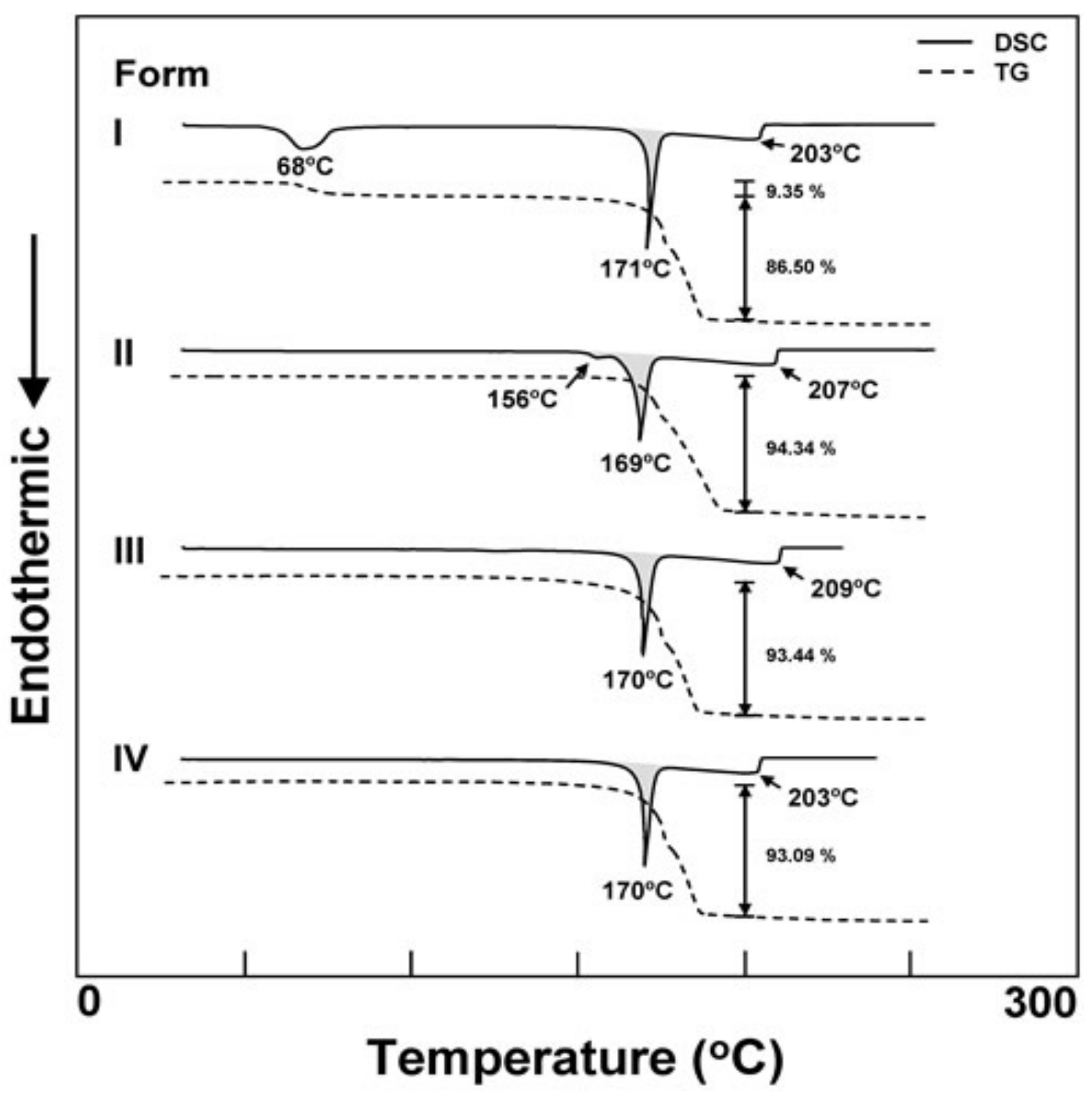

Figure 1. DSC and TG curves of four GBP polymorphs 
Figure 2 indicates the FTIR spectra of GBP forms I-IV. Since GBP displays a zwitterion in the solid state (18-19), there was no IR peak absorption in the usual -NH stretching regions (3500-3300 $\mathrm{cm}^{-1}$ ). However, an IR band absorption in the region of 3200-2800 $\mathrm{cm}^{-1}$ was observed, which was due to the $-\mathrm{NH}_{3}{ }^{+}$stretching vibration for all GBP polymorphs (27). The broad peak at $3300 \mathrm{~cm}^{-1}$ for GBP form I might be attributed to the stretching vibrational modes of hydroxyl groups of water molecules in the GBP hydrate. The peaks near at 2123-2200 $\mathrm{cm}^{-1}$ corresponded to the distinct side chain and/or $\mathrm{CN}$ stretching vibration of all GBP polymorphs. In the region of $1700-1500 \mathrm{~cm}^{-1}$, the IR bands could be assigned as the ionized asymmetric carboxylate and $\mathrm{NH}_{3}{ }^{+}$deformation vibration, respectively. From 1500 to $1350 \mathrm{~cm}^{-1}$, these bands corresponded also to the asymmetric carboxylate band and/or $\mathrm{CH}_{2}$ deformation band. Below $1350 \mathrm{~cm}^{-1}$, these peaks might be used as a fingerprint of GBP. Table I shows the IR spectral peak positions of four GBP polymorphs determined by this study and obtained from patent literature (15). Obviously, the IR peak positions determined by this study were consistent with that of the data obtained from patent, confirming that these four GBP polymorphs prepared by present study were the patented polymorphic forms I, II, III and IV of GBP.

Fig. 2

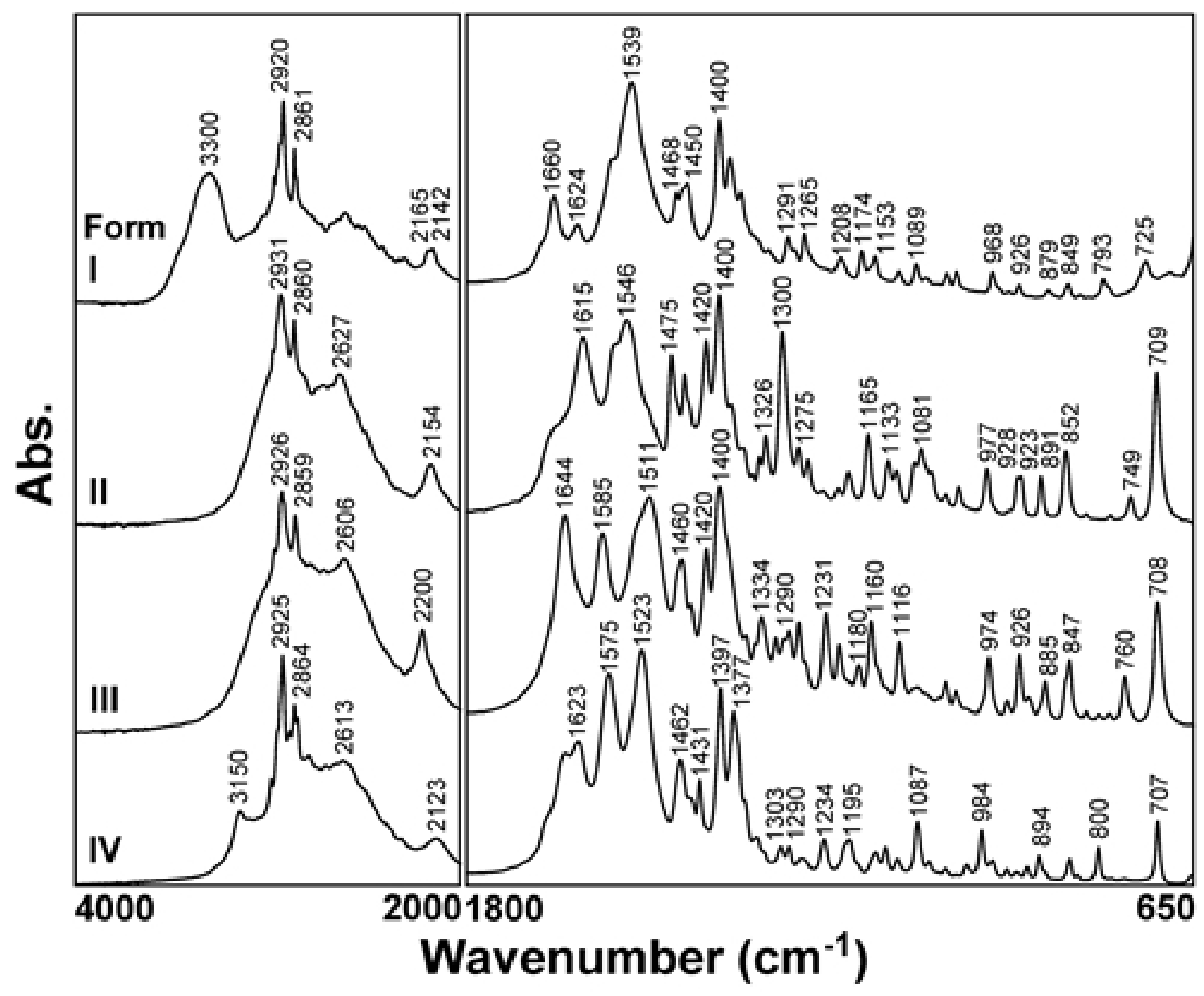

Figure 2. FTIR spectra of four GBP polymorphs. 


\begin{tabular}{cccc}
\hline \multicolumn{4}{c}{ Table 1. IR spectral peak positions of four GBP polymorphs prepared by this study and obtained from patent. } \\
\hline GBP Form I & GBP Form II & GBP Form III & GBP Form IV \\
\hline $1660(1664)$ & $1615(1615)$ & $1644(1644)$ & $1623(1622)$ \\
$1624(1624)$ & $1546(1546)$ & $1585(1586)$ & $1575(1574)$ \\
$1539(1542)$ & $1475(1476)$ & $1511(1510)$ & $1523(1521)$ \\
$1291(1292)$ & $1420(1420)$ & $1460(1460)$ & $1462(1462)$ \\
$1174(1175)$ & $1400(1400)$ & $1420(1420)$ & $1431(1431)$ \\
$1153(1154)$ & $1336(1337)$ & $1400(1402)$ & $1397(1397)$ \\
$968(968)$ & $1326(1327)$ & $1334(1333)$ & $1377(1376)$ \\
$926(926)$ & $1300(1300)$ & $1311(1311)$ & $1303(1302)$ \\
$879(880)$ & $1165(1165)$ & $1290(1290)$ & $1290(1289)$ \\
$725(726)$ & $1133(1133)$ & $1180(1180)$ & $1234(1235)$ \\
& $1119(1120)$ & $1160(1160)$ & $1196(1196)$ \\
& $977(976)$ & $1116(1115)$ & $1087(1086)$ \\
& $928(928)$ & $974(974)$ & $984(985)$ \\
& $923(922)$ & $945(945)$ & $894(894)$ \\
& $891(890)$ & $926(926)$ & $847(846)$ \\
& $749(749)$ & $885(885)$ & $800(800)$ \\
& $709(709)$ & $760(760)$ & $707(707)$ \\
& & $708(708)$ & \\
\hline
\end{tabular}

It is well known that X-ray powder diffraction is a powerful and useful technique for the identification of phases in powder form. This technique is also used to establish the possible differences in the crystal form of polymorphs. The X-ray powder diffraction patterns of these four GBP polymorphs are shown in Fig. 3. The sharp peaks in the $5 \sim 40^{\circ} 2 \theta$ region suggested that all the polymorphs were highly crystalline. Moreover, substantial differences in the position and intensity of the diffraction peaks were revealed for these four GBP polymorphs. The peak positions of X-ray powder diffraction patterns for these GBP polymorphs were also similar to that of the position and pattern reported in a patent (15), implying that the polymorphic forms I, II, III and IV of GBP prepared by this study were also identified.

\section{Thermal-induced polymorphic interconversion of GBP polymorphs by hot-stage FTIR microspectroscopy}

Three-dimensional plot of the FTIR spectra of GBP form I as a function of temperature is displayed in
Fig.4-A. The thermal-related changes in peak intensity for several specific spectra are also displayed. It clearly indicates that the thermal-dependent IR spectral contour and peak intensity of GBP form I were markedly changed with four-step process within temperature ranges at $30-55^{\circ} \mathrm{C}, 55-115^{\circ} \mathrm{C}, 115-140^{\circ} \mathrm{C}$ and $140-190^{\circ} \mathrm{C}$. The former temperature range at $30-55^{\circ} \mathrm{C}$ was due to the intact GBP form I without alteration. The last temperature range beyond $140^{\circ} \mathrm{C}$ might be explained by the intramolecular cyclization in GBP structure and the formation of GBP-lactam, due to the appearance of IR spectral peak at $3444 \mathrm{~cm}^{-1}$ for water dehydrated and liberated, as well as at 1692 $\mathrm{cm}^{-1}$ for lactam formation of GBP. Since GBP form I was a monohydrate, it was dehydrated beyond $55^{\circ} \mathrm{C}$ and caused the contribution of broad peak at $3444 \mathrm{~cm}^{-1}$. This was different from that of the peak at $3350 \mathrm{~cm}^{-1}$ mainly attributed from water liberated via intramolecular cyclization in GBP structure found in our previous study (13). From the changes in IR spectral contour and peak intensity, the appearance of several peaks at 2190, 1641, 1585 and $760 \mathrm{~cm}^{-1}$ as well as at $3140,2117,1566,1456$, 


\section{Fig. 3}

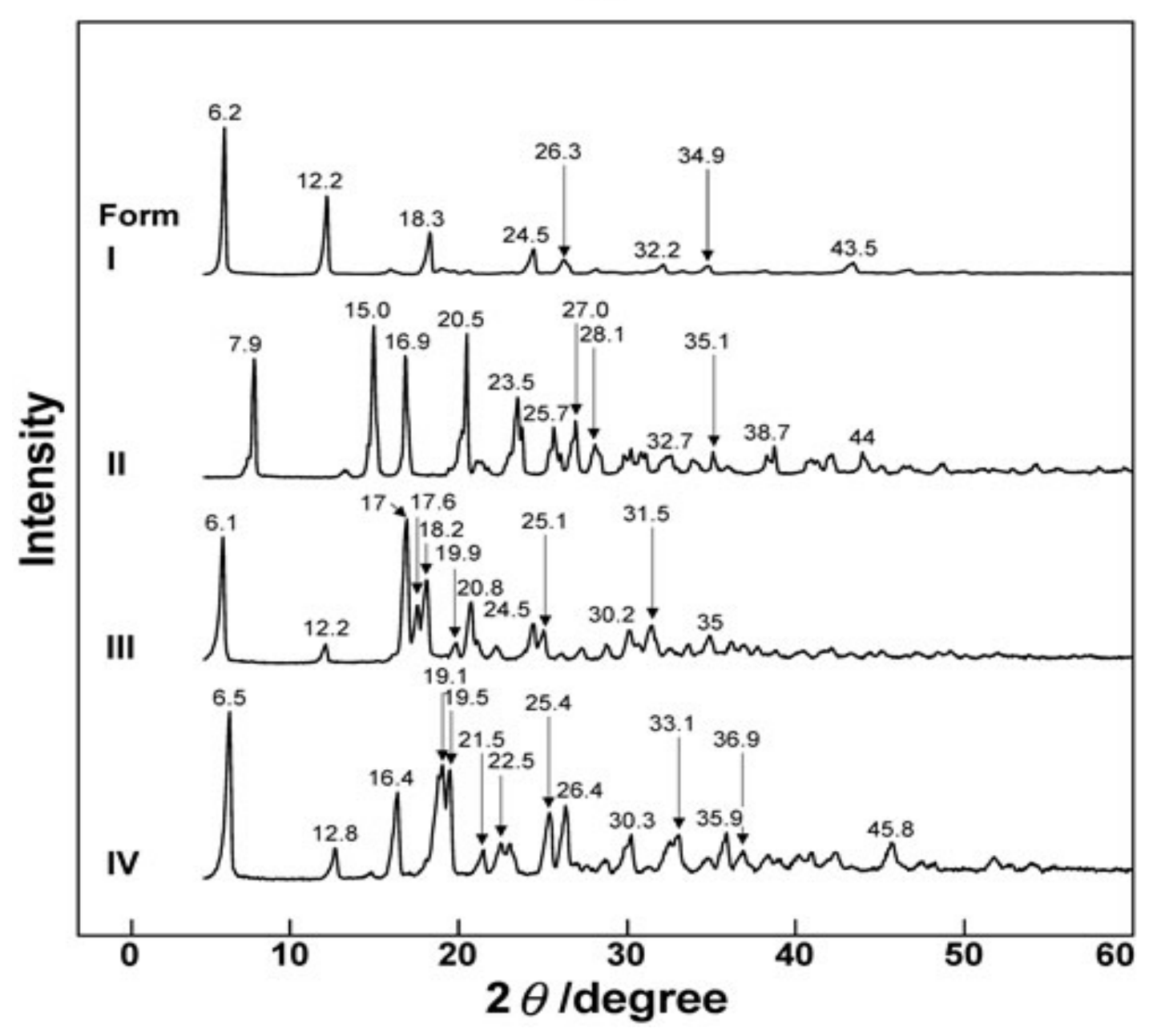

Figure. 3. X-ray powder diffraction patterns of four GBP polymorphs

1375 and $1078 \mathrm{~cm}^{-1}$ seemed to be similar to that of IR spectra of GBP forms III and IV. In addition, Figure 4-B shows the representative IR spectra of $90^{\circ} \mathrm{C}$ - and $125^{\circ} \mathrm{C}$-heated samples, as compared with the IR spectra of GBP forms I, III and IV. Obviously, except the $3444 \mathrm{~cm}^{-1}$ for water dehydrated and liberated, the representative IR spectra of $90^{\circ} \mathrm{C}$ - or $125^{\circ} \mathrm{C}$-heated sample were very close to that of the IR spectra of GBP forms III or form IV shown in Fig. 2. It should be noted that the IR spectra of both heated samples at $90^{\circ} \mathrm{C}$ and $125^{\circ} \mathrm{C}$ were somewhat different from that of the IR spectra of GBP form III or IV stored at room temperature. This suggests that GBP form I might previously be dehydrated under the course of heating process and then directly transformed to GBP form III, and continuously converted to GBP form IV.
Figure 5 also reveals the three-dimensional plot of the FTIR spectra of GBP form II as a function of temperature. Obviously, the changes having three-step process within temperature ranges of $30-126^{\circ} \mathrm{C}, \quad 126-150^{\circ} \mathrm{C}$ and $150-167^{\circ} \mathrm{C}$ were observed from the IR spectral contour and IR peak intensity. The IR spectra maintained the same pattern from 30 to $126^{\circ} \mathrm{C}$ for intact GBP form II, but several new peaks at 3140,2117, 1567, 1456 and $1087 \mathrm{~cm}^{-1}$ due to GBP form IV appeared over $126^{\circ} \mathrm{C}$. By continuous heating, the IR spectra at $3350 \mathrm{~cm}^{-1}$ for water liberated via intramolecular cyclization in GBP structure and at $1701 \mathrm{~cm}^{-1}$ for lactam formation of GBP were found (13). It clearly reveals that except for the formation of GBP-lactam, the GBP form II might be directly transformed to GBP form IV under heating. 
Fig. 4-A

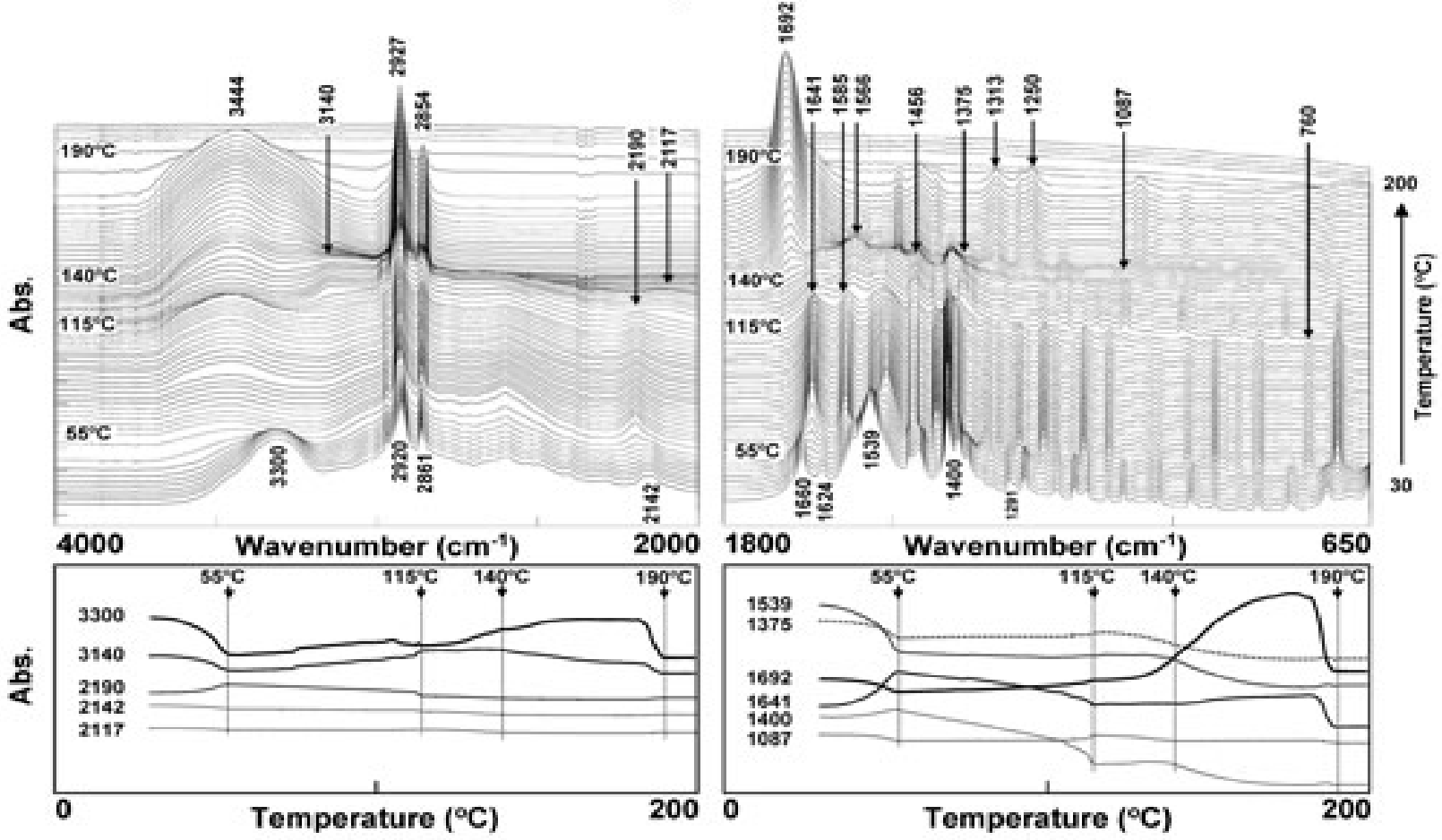

Figure. 4-A. Three-dimensional plot of the FTIR spectra for GBP form I as a function of temperature and the thermal-related changes in peak intensity for several specific spectra.

Fig. 4-B

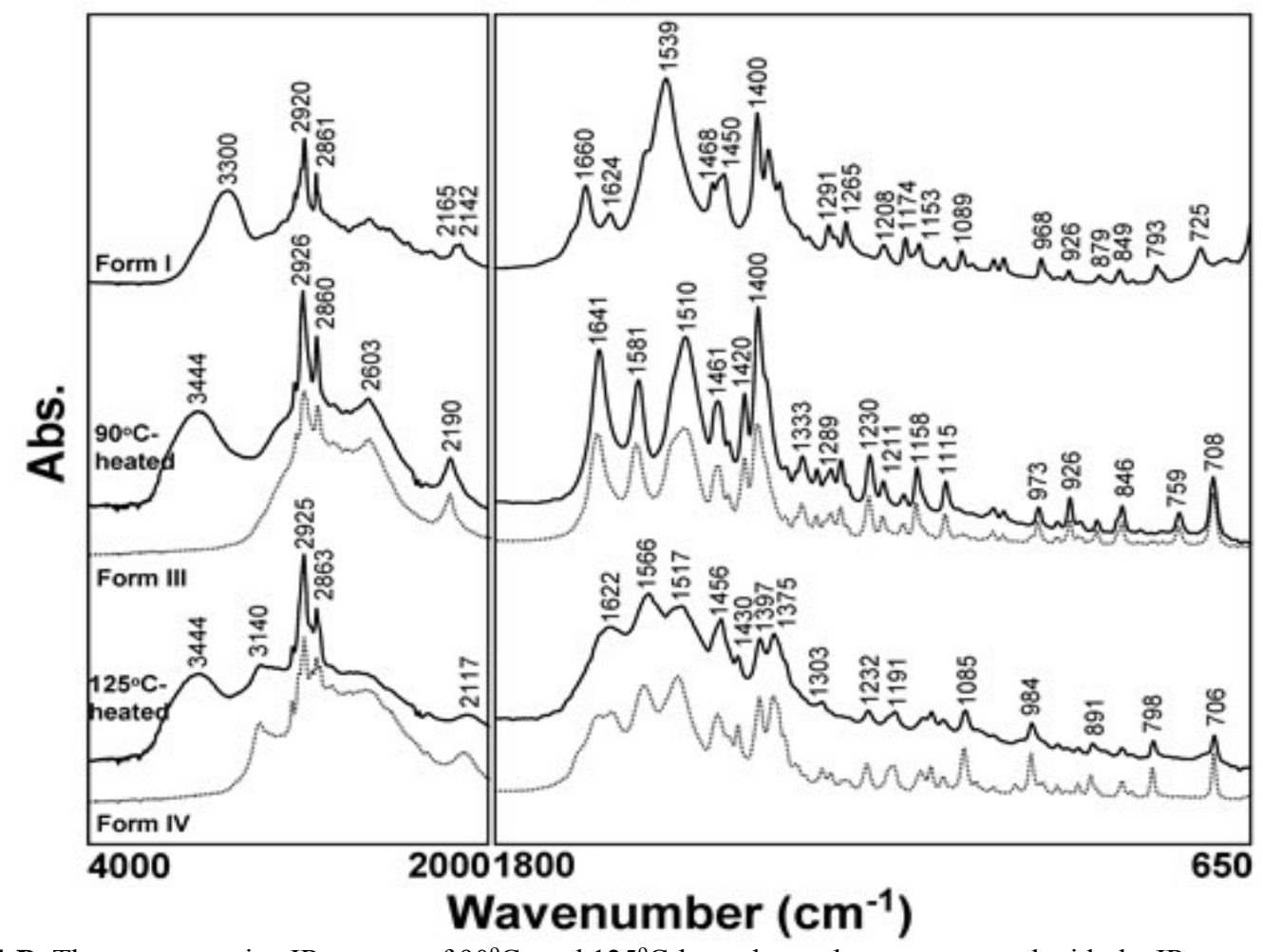

Figure 4-B. The representative IR spectra of $90^{\circ} \mathrm{C}$ - and $125^{\circ} \mathrm{C}$-heated samples, as compared with the IR spectra of GBP forms I, III and IV. 


\section{Fig. 5}

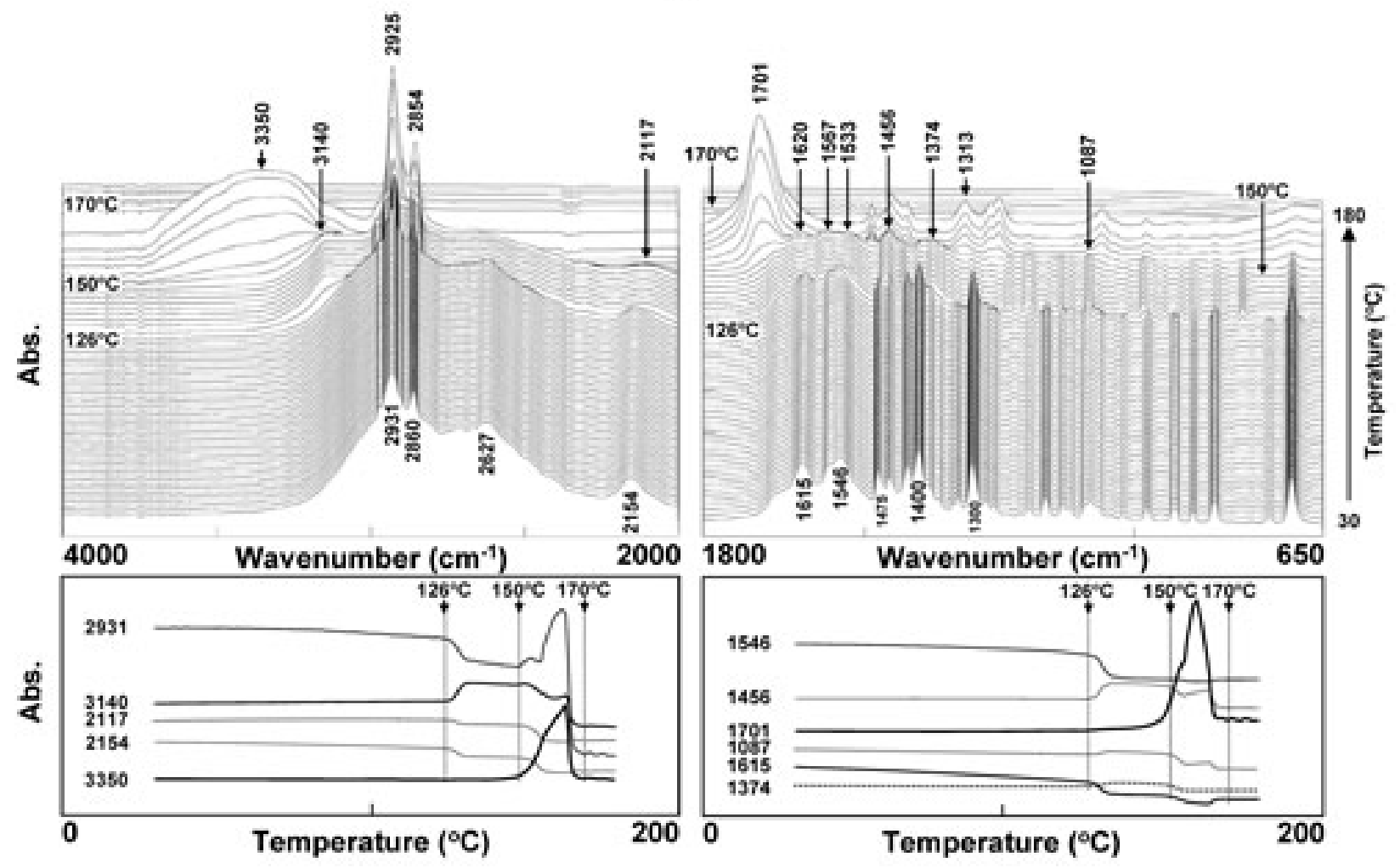

Figure 5. Three-dimensional plot of the FTIR spectra for GBP form II as a function of temperature and the thermal-related changes in peak intensity for several specific spectra.

In a similar heating process, the three-step changes within temperature ranges of $30-75^{\circ} \mathrm{C}$, $75-150^{\circ} \mathrm{C}$ and $150-181^{\circ} \mathrm{C}$ were observed from the IR spectral contour and IR peak intensity of GBP form III, as shown in Fig. 6. The IR spectra of GBP form III within $30-75^{\circ} \mathrm{C}$ maintained the same IR spectral pattern, but several new peaks at 3140 , 1456, 1374, and $1087 \mathrm{~cm}^{-1}$ close to that of IR spectra of GBP form IV gradually appeared in the temperature range of $75-150^{\circ} \mathrm{C}$. Beyond $150^{\circ} \mathrm{C}$, the IR spectra at 3350 and $1701 \mathrm{~cm}^{-1}$ were also observed due to the water liberated via intramolecular cyclization in GBP structure and the lactam formation of GBP (13). There is no doubt that except for the formation of GBP-lactam, the GBP form III might be also directly transformed to GBP form IV. When the GBP form IV sample was previously compressed between two $\mathrm{KBr}$ plates and then heated, the changes in IR spectral contour and IR peak intensity of GBP form IV is shown in Fig. 7. Except the formation of GBP-lactam beyond $150^{\circ} \mathrm{C}$, the IR spectral contour and IR peak intensity of GBP form IV were almost the same. This indicates that there was no thermal effect on the polymorphic transformation of GBP form IV.

\section{CONCLUSIONS}

In the present study, four GBP polymorphs had been previously prepared and characterized by means of microspectroscopic, calorimetric and diffraction techniques. A one-step novel microscopic hot-stage FTIR spectroscopy was successfully applied to simultaneously and continuously investigate the progressive steps of thermal-induced polymorphic interconversion of each GBP polymorph. GBP form I was previously dehydrated and transformed to form III, and then converted to form IV. GBP forms II and III were directly transformed to form IV via thermal-induced polymorphic interconversion. However, GBP form IV might be the last polymorph before the intramolecular lactamization of GBP. 
Fig. 6

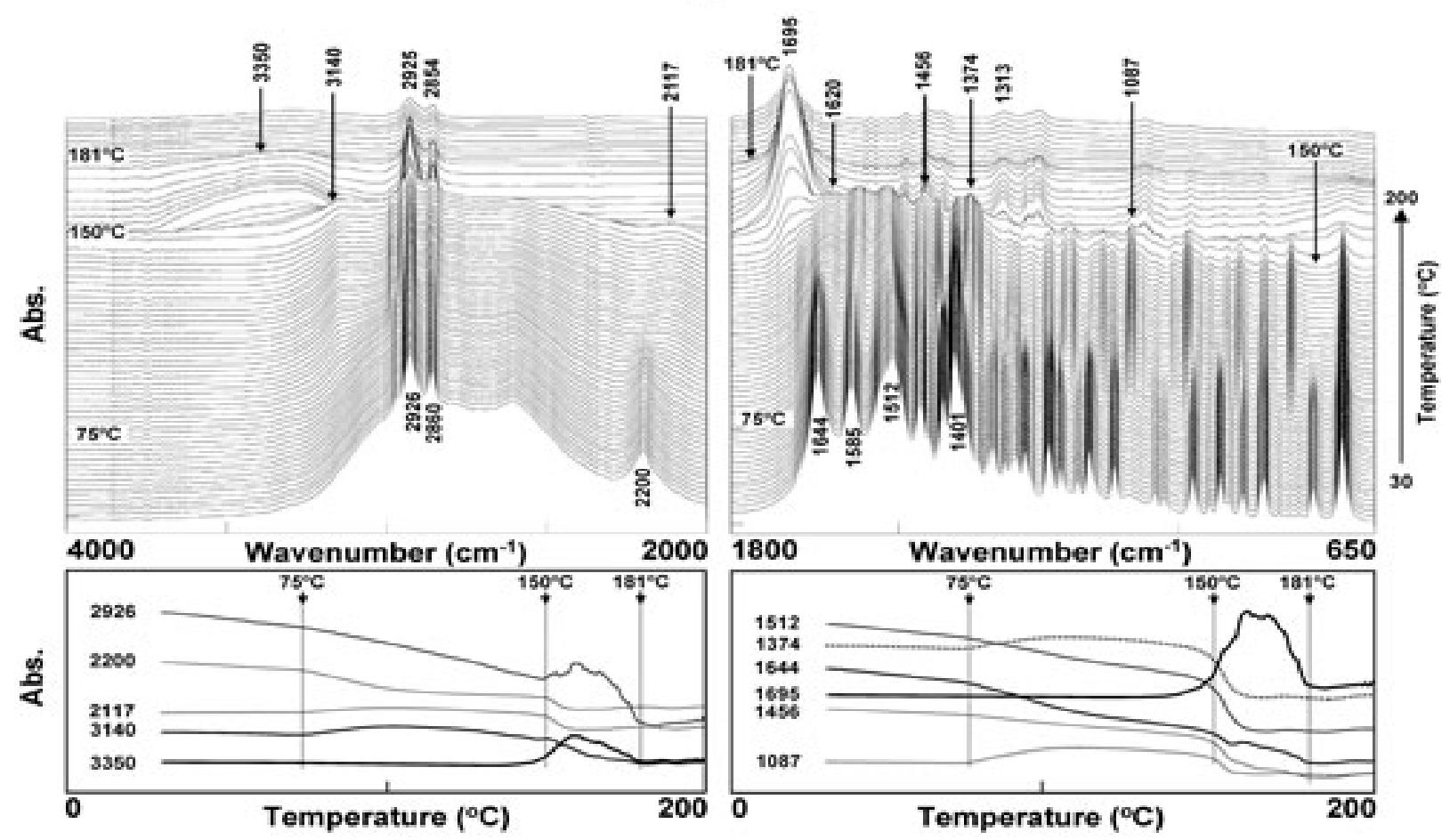

Figure 6. Three-dimensional plot of the FTIR spectra for GBP form III as a function of temperature and the thermal-related changes in peak intensity for several specific spectra.

Fig. 7

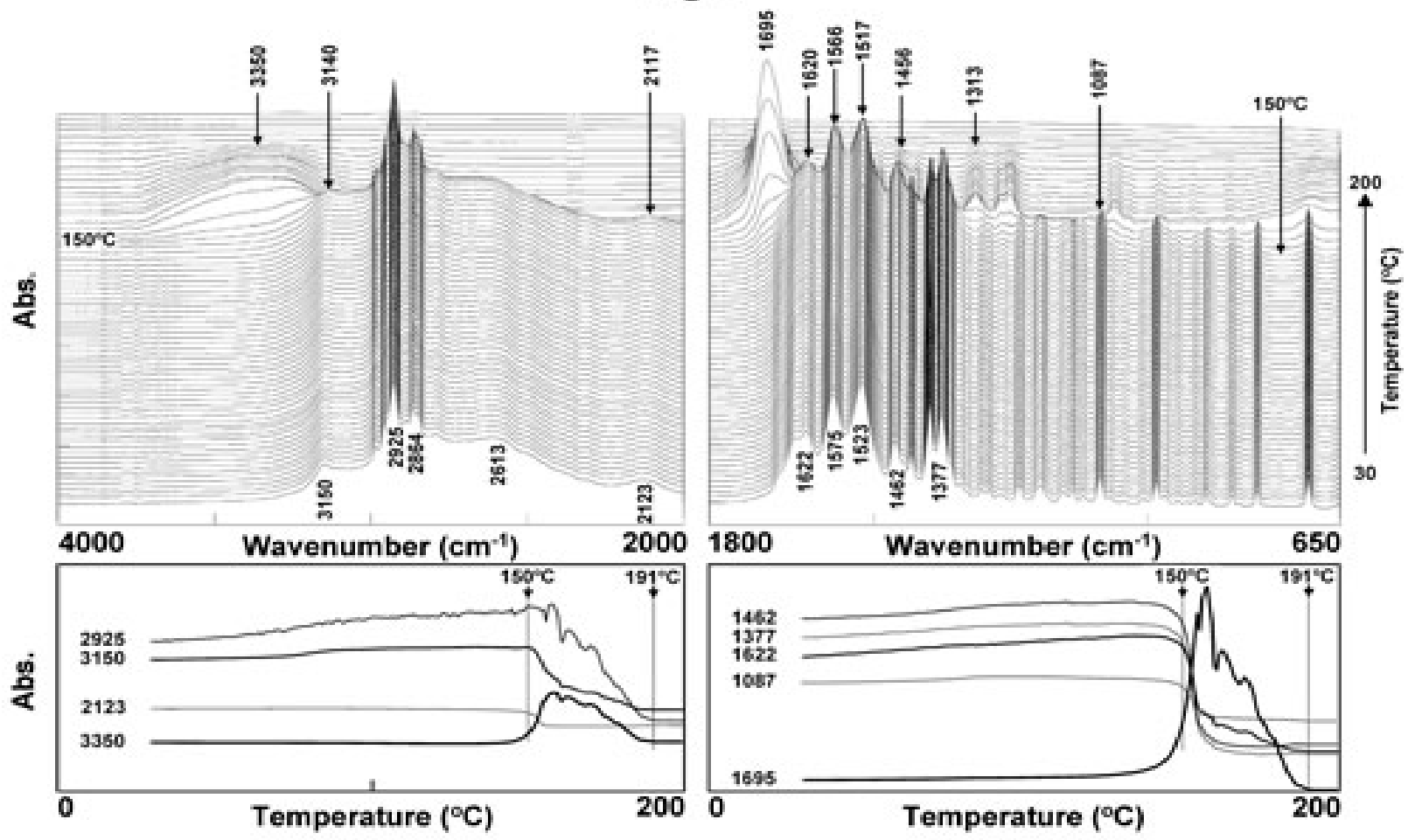

Figure 7. Three-dimensional plot of the FTIR spectra for GBP form IV as a function of temperature and the thermal-related changes in peak intensity for several specific spectra. 


\section{ACKNOWLEDGEMENTS}

We would like to acknowledge BioTech One Inc. (San-Chung City, Taipei Hsien, Taiwan, ROC) for kindly providing a powder X-ray diffractometer for sample analysis. The authors wish to thank the reviewer and editor for their constructive comments that helped improve the manuscript.

\section{REFERENCES}

1. Goa KL, Sorkin EM. Gabapentin. A review of its pharmacological properties and clinical potential in epilepsy. Drugs. 46: 409-427, 1993.

2. Dobecki DA, Schocket SM, Wallace MS. Update on pharmacotherapy guidelines for the treatment of neuropathic pain. Curr Pain Headache Rep. 10: 185-190, 2006.

3. Johnson RW, Wasner G, Saddier P, Baron R. Postherpetic neuralgia: epidemiology, pathophysiology and management. Expert Rev Neurother. 7: 1581-1595, 2007.

4. Moretti R, Torre P, Antonello RM, Cazzato G. Gabapentin as a possible treatment of behavioral alterations in Alzheimer disease (AD) patients. Eur J Neurol. 8: 501-502, 2001.

5. Ananda K, Aravinda S, Vasudev Prema G, Raja Muruga Poopathi K, Sivaramakrishnan $H$, Nagarajan K, Shamala N, Balaram P. Stereochemistry of gabapentin and several derivatives: Solid state conformations and solution equilibria. In: Current Science, 85: 1002-1011, 2003.

6. Bryans JS, Horwell DC, Ratcliffe GS, Receveur JM, Rubin JR. An in vitro investigation into conformational aspects of gabapentin. Bioorg Med Chem. 7: 715-721, 1999.

7. Sills GJ. The mechanisms of action of gabapentin and pregabalin. Curr Opin Pharmacol. 6: 108-113, 2006.

8. Yamauchi T, Kaneko S, Yagi K, Sase S. Treatment of partial seizures with gabapentin: double-blind, placebo-controlled, parallel-group study. Psychiatry Clin Neurosci. 60: 507-515, 2006.

9. Byrn SR, Pfeiffer RR, Stowell JG (eds.). Solid-state Chemistry of Drugs. $2^{\text {nd }}$ Ed., SSCI, Inc., West Lafayette, Indiana, USA. 1999.

10. Byrn SR, Xu W, Newman AW. Chemical reactivity in solid-state pharmaceuticals: formulation implications. Adv Drug Deliv Rev. 48: 115-136, 2001.

11. US FDA. Guidance for Industry. ANDAs: Pharmaceutical. Solid Polymorphism. Chemistry, Manufacturing, and Controls Information. 2007.

12. Ciavarella AB, Gupta A, Sayeed VA, Khan MA, Faustino PJ. Development and application of a validated HPLC method for the determination of gabapentin and its major degradation impurity in drug products. J Pharm Biomed Anal. 43: 1647-1653, 2007.

13. Hsu CH, Lin SY. Rapid examination of the kinetic process of intramolecular lactamization of gabapentin using DSC-FTIR. Thermochimica Acta. 486: 5-10, 2009.

14. Pesachovich M, Singer C, Pilarski G. Preparation of gabapentin. US Patent 6255526, 2001.

15. Satyanarayana, C., Ramanjaneyulu, G. S., Kumar, I. V. S. Novel polymorph of gabapentin and its conversion to gabapentin Form-II. WO 2004/110342, 2004.

16. Kumar Y, Khanduri CH, Ganagakhedkar KK, Chakraborthy R, Dorwal HN, Rohatgia A, Panda AK. Crystalline gabapentin. WO 2004/106281, 2004.

17. Braga D, Grepioni F, Maini L, Rubini K, Polito M, Brescello R, Cotarca L, Duarte MT, André V, Piedade MFM. Polymorphic gabapentin: thermal behaviour, reactivity and interconversion of forms in solution and solid-state. New J. Chem., 32: 1788-1795, 2008.

18. Reece HA, Levendis DC. Polymorphs of gabapentin. Acta Cryst. C64: o105-o108, 2008.

19. Ibers J A. Gabapentin and gabapentin monohydrate. Acta Cryst. Cryst. Struct. Commun. 57C: 641-643, 2001.

20. Butler DE, Greenman BJ. Gabapentin monohydrate and a process for producing the same. US Patent 4894476, 1990.

21. Medichem SA, Bosch I llado J, Arnalot Aguilar C, Burgarolas Montero MC. Process and Methods for the Preparation of Gabapentin and Its Intermediates. WO2006090208, 2006.

22. Vasudev PG, Aravinda S, Ananda K, Veena SD, Nagarajan K, Shamala N, Balaram P. Crystal structures of a new polymorphic form of gabapentin monohydrate and the e and $\mathrm{z}$ isomers of 4-tertiarybutylgabapentin. Chem Biol Drug Des. 73: 83-96, 2009.

23. Wenger $\mathrm{M}$, Bernstein J. An alternate crystal form of gabapentin: A cocrystal with oxalicaAcid. Cryst. Growth Des., 8: 1595-1598,2008.

24. Lin SY, Chien JL. In vitro simulation of solid-solid dehydration, rehydration, and solidification of trehalose dihydrate using thermal and vibrational spectroscopic techniques, Pharm. Res. 20: 1926-1931, 2003.

25. Wang SL, Lin SY, Hsieh TF, Chan SA. Thermal behavior and thermal decarboxylation of 10-hydroxycamptothecin in the solid sate J. Pharm. Biomed. Anal. 43: 457-463, 2007.

26. Cutrignelli A, Denora N, Lopedota A, Trapani A, Laquintana V, Latrofa A, Trapani G, Liso G. Comparative effects of some hydrophilic excipients on the rate of gabapentin and baclofen lactamization in lyophilized formulations. Int $\mathrm{J}$ Pharm. 332: 98-106, 2007. 
27. Chimatadara SA, Basavaraja T, Thabaja KA, Sharanappa T. Ruthenium(III) catalysed oxidation of gabapentin (neurontin) by diperiodatocuprate(III) in aqueous alkaline medium: A kinetic and mechanistic study. J. Mol. Catalysis A: Chemical. 267: 65-71, 2007. 